\title{
Mapeamento da vulnerabilidade dạ águas subterrâneas e uso do solo na área urbana do município de Nova Palma, RS.
}

\author{
Mapping the vulnerability of groundwater and land use in the urban area of the \\ municipality of Palma Nova, RS.
}

\author{
Carlos Alberto Löbler¹; José Luiz Silvério da Silva²; Lueni Gonçalves Terra³ \\ ${ }^{1}$ Geografo, Mestrando do Programa de Pós-graduaçaõ em Engenharia Ambiental da Universidade Federal de \\ Santa Maria(PPGEAmb/UFSM), Santa Maria, Brasil. \\ ${ }^{2}$ Professor Doutor do Departamento de Geociências da Universidade Federal de Santa, Santa Maria, Brasil. Maria \\ ${ }^{3}$ Geógrafa, Mestranda do Programa de Pós-Graduação em Engenharia Civil da Universidade Federal de Santa \\ Maria (PPGEC/UFSM), Santa Maria, Brasil.
}

\begin{abstract}
Resumo
Este artigo objetiva análisar a vulnerabilidade à contaminação das águas subterrâneas da área urbana do município de Nova Palma com base no sistema GOD e correlacionar com o uso do solo na área e os pontos potenciais de contaminação. Foram coletados dados no sítio do CPRM/SIAGAS, em "in loco" e em imagem do Google Earth. Os dados foram processados dentro do ambiente SIG do ArcGIS 10. Os resultados mostraram que a área urbana do município apresenta dois postos de combustíveis e um cemitério como fontes potenciais de contaminação, esses estão localizados em áreas de alta vulnerabilidade do aquífero. O mapeamento de uso do solo mostrou que a maior percentual de ocupação é de área construída, seguido de floresta, solo exposto e campo. Enquanto que a classe de vulnerabilidade alta é a que possui maior percentual de ocorrência no mapeamento de vulnerabilidade de águas subterrâneas. Sugere-se grande atenção e observância nos critérios da legislação quanto ao monitoramento das fontes poluidoras já existentes e às que ainda poderão se instalar.
\end{abstract}

Palavras-chave: Aquífero, Contaminação, Uso do solo.

\begin{abstract}
This study analyzed the vulnerability to contamination of groundwater in the urban area of the municipality of Nova Palma based on GOD system and also correlated with land use in the urban area and potential points of contamination. Data were collected at the website of the CPRM / SIAGAS and data of Field and image in Google Earth. Data were processed within SIG of ArcGIS 10. Results showed that the urban area has two gas stations and a cemetery as potential sources of contamination, these are located in areas of high vulnerability of the aquifer. The mapping of land use showed that the highest percentage of occupancy is constructed area, followed by forest, bare soil and field. While the high vulnerability class is the one with largest pecentual of occurrence in mapping groundwater vulnerability. It is suggested great attention and compliance criteria in the legislation regarding the monitoring of existing and which may still install pollution sources.
\end{abstract}

Keywords: aquifer, contamination Use of soil. 


\section{Introdução}

$\mathrm{A}$ s águas subterrâneas, assim como os recursos hídricos como um todo, são objetos de preocupação e estudos, que objetivam o uso racional e que melhor atendam as necessidades do homem. Além disso esses recursos podem ser determinantes no desenvolvimento socioeconômico de uma sociedade.

Custodio e Silva Junior (2008) destacam que as águas subterrâneas são uma parte essencial do ciclo hidrológico, caracterizando-se pelo longo tempo de residência, ubiquidade e pequena variabilidade composicional. $\mathrm{O}$ fluxo estável e as propriedades químicas pouco variáveis das águas subterrâneas têm um papel fundamental nos processos geológicos e biológicos.

No entanto, o crescimento urbano desordenado, ao gerar concentração de poluentes que são mal gerenciados, cria um ambiente propício à poluição das reservas hídricas subterrâneas. Assim, verifica-se a importância de estudos que objetivem verificar a vulnerabilidade dessas reservas.

Foster et al. (2013) consideram que os estudos de vulnerabilidade natural de aquíferos destinam-se a representar a variação do nível de proteção natural ou a capacidade de atenuação do contaminante na zona de solo insaturado ou zona de semi-confinamento da água. Portanto, as características geológicas do meio nos indicam alguns fatores, como a capacidade da água subterrânea de infiltrar e a capacidade de percolação e infiltração de poluentes.

A qualidade da água subterrânea está intimamente ligada à cobertura do solo. Araújo et al. (2009) lembram que a capacidade de infiltração é afetada pelo tipo de vegetação e manejo. Logo, há grande necessidade em conhecer o uso e a ocupação do solo.

No estudo de Fiquepron et al. (2013) foi realizado uma comparação entre a área florestada e a qualidade da água bruta que é utilizada para abastecimento doméstico. Os autores constataram com o estudo que a floresta tem um efeito positivo na qualidade da água bruta em comparação com outros usos da terra e que o preço final da água, que chega até o consumidor é amplamente influenciada pelo uso do solo.

Todo uso do solo influência na qualidade da água, uns mais, outros menos. No estudo de Ribolzi et al (2011) os autores observaram que o adensamento populacional é $o$ grande responsável pela queda da qualidade das águas superficiais, principalmente. Ainda, os autores citaram a importância da cobertura florestal para a filtragem de componentes nocivos aos recursos hídricos.

Os maiores problemas de áreas com intensas urbanizações estão ligados aos despejos de esgotos, cemitérios e postos de combustíveis. Dentro dos esgotos domésticos existem variados elementos poluidores, como produtos farmacêuticos e de higiene pessoal (Kuroda et al., 2012).

Nos cemitérios o principal poluidor dos recursos hídricos subterrâneos é o necrochorume que é produ- zido a partir da decomposição dos corpos sepultados (Kemerich et al., 2011). Já, os principais poluentes, em postos de combustíveis que operam com diesel, gasolina e álcool são os BTEX (benzeno, tolueno, etileno e xileno), além dos hidrocarbonetos totais de petróleo (Löbler et al., 2013).

A regulamentação desses pontos potencias de poluição são feitos no Brasil pelo CONAMA (Conselho Nacional de Meio Ambiente), o qual através de critérios e normas regulamenta as atividades relacionados a postos de combustíveis (Resolução 368/2006) e as relacionadas a cemitérios (Resolução 335/2003). Já os esgotos, tanto sanitários quanto domésticos estão regulamentados pela resolução 377/2006.

Este trabalho objetivou analisar a vulnerabilidade à contaminação das águas subterrâneas da área urbana do município de Nova Palma com base no sistema GOD (Foster et al. 2006) e a relação com uso do solo na área e os pontos potenciais de contaminação. Foram considerados como pontos de contaminação os postos de combustíveis e os cemitérios existentes na área.

O meio urbano do município de Nova Palma é abastecido por poços tubulares, que captam água do Sistema Aquífero Guarani (SAG). Essas captações são gerenciadas pela CORSAN (Companhia Riograndense de Saneamento) que possui uma série de normas e padrões qualitativos e quantitativos.

\section{Metodologia}

\subsection{Caracterização da área de estudo}

Segundo dados demográficos do IBGE (Instituto Brasileiro de Geografia e estatística) de 2013, o município de Nova Palma possui 6.342 habitantes, sendo que $48,6 \%$ vivem na área urbana do município enquanto que 51,4\% na área rural. A base da economia é agrícola com alguma contribuição da indústria moveleira e de processamento de alimentos.

Nova Palma situa-se na região central do estado do Rio Grande do Sul, fazendo parte da região conhecida como Quarta Colônia de Imigração Italiana. Geologicamente está inserida na Depressão Central na borda da bacia do Paraná, constituída de rochas sedimentares clásticas formadoras do Sistema. O município esta dentro da microrregião de Restinga Seca e dentro da mesorregião Centro Ocidental Sul Rio-Grandense, segundo divisões do IBGE (Instituto Brasileiro de Geografia e Estatística). Hidrograficamente está inserida na bacia do rio Jacuí que faz parte da bacia hidrográfica do Guaíba ( $G$ - 50, Secretaria Estadual de Meio Ambiente/SEMA, 2005) (figuras 1 e 2).

\subsection{Coleta de dados}

Os poços tubulares selecionados para a pesquisa foram 
buscados junto ao sítio da CPRM, no sistema SIAGAS (Sistema de Informações de Águas Subterrâneas) onde foram selecionados poços localizados na área urbana do município e que possuíam todos os dados necessários para a aplicação do sistema GOD (Foster et al. (2006). Os dados necessários são referentes ao nível estático do poço, e as características geológicas do meio aquífero.

Fraga et al. (2013) testaram três métodos diferentes de determinação de vulnerabilidade à contaminação de águas subterrâneas na Bacia do Rio do Sôrdo em Portugal. De acordo com os autores, o sistema GOD é muito eficiente para estudos que exijam rapidez e confiança nos resultados.

Os pontos potencialmente contaminantes foram localizados no município, e posteriormente foi realizada a leitura de coordenadas com uso do Global Position System/ GPS Garmim Etrex manual. Com isso foram localizados dois postos de combustíveis e um cemitério.

A partir disso, localizaram-se os pontos em imagem orbital do Google Earth e criou-se uma feição do tipo polígono que o representa. No programa ArcGIS foi transformado em formato Shapefile, o que permitiu a sobreposição de informações. A imagem para gerar o mapa de uso do solo foi retirada do Google Earth.

\subsection{Método de vulnerabilidade}

Para determinação da vulnerabilidade a contaminação foi utilizado o sistema GOD de Foster et al., (2006) que caracterizam a vulnerabilidade intrínseca (natural) do aquífero à contaminação, adotando os seguintes parâmetros: (G) Tipo de ocorrência da água subterrânea; (O) Classificação dos estratos acima da zona saturada do aquífero, em termos do grau de consolidação e caráter litológico; (D) Determinação da profundidade do nível freático que é o nível estático do aquífero medido na "boca do poço".

Após a pontuação das três etapas é feito o produto dos três valores, obtendo-se a(s) classe(s) de vulnerabilidade da qual pertencem às águas. Esta vulnerabilidade pode ser classificada como: desprezível $(0$ a 0,1$)$, baixa $(0,1$ a $0,3)$, média $(0,3$ a 0,5$)$, alta $(0,5$ a 0,7$)$ e extrema $(0,7$ a 1,0$)$.

\subsection{Espacialização dos dados.}

A imagem do Google Earth usada para gerar as classes do uso do solo foi georreferenciada com o uso do sistema de pontos de referência em comum, para isso utilizou-se o shape dos poços. Com o shape dos poços, após serem importados por tabela no formato $x l s$, procurou-se na imagem a localização desses poços e atribui-se, com o uso da ferramenta georeferencing, a ligação entre eles.

Para a delimitação da área urbana do município foi usado o shape disponibilizado pelo IBGE onde foram realizados ajustes utilizando-se imagem do Google Earth para o ano de 2011. Esses ajustes serviram para ter uma versão atualizada da área urbana do município.
As interpolações feitas na pesquisa foram realizadas com o interpolador matemático Krigagem, pois foi o que apresentou melhores resultados para a amostra.

Adotou-se o sistema de coordenadas UTM, adotando-se o fuso 22, o Datum horizontal SAD 69, e o Datum vertical Porto de Imbituba/Santa Catarina. Esse sistema também é usado pelo SIAGAS da CPRM.

\section{Discussão dos resultados}

A partir da criação do mapa do uso do solo com uso da imagem do Google Earth foi possível quantificar a área de abrangência das classes florestas, campo, solo exposto e uso do solo para a área urbana de Nova Palma (Tabela 1). A classe água não foi visualizada na área

Constatou-se que as classes área construída e florestas ocupam as maiores áreas avaliadas, 559,69 km² e 557,66 $\mathrm{km}^{2}$ respectivamente do total de $1918,17 \mathrm{~km}^{2}$ da área de estudo. As classes solo exposto e campo representaram, respectivamente, $25,02 \%$ e $16,73 \%$ do total mapeado, sendo menos significantes.

As classes de uso do solo possuem características distintas quanto à infiltração de água para o lençol freático e quanto ao potencial de contaminação. Superfícies com maior percentual de cobertura vegetal possuem maior capacidade de infiltração, chegando ao menor índice em áreas concretadas/pavimentadas e favorecem um maior escoamento superficial.

Mesmo sendo característico de ambientes urbanos possuírem a classe área construída de uso solo, como a de maior abrangência, no caso de Nova Palma obteve-se certo equilíbrio entre as classes área construída e floresta. Isso pode estar associado à delimitação ampliada da área analisada, para que fossem contemplados poços localizados próximos aos limites da área urbana do município. Ainda, pode estar relacionado ao fato das cidades do interior serem mais arborizadas e possuírem mais terrenos sem construção.

Tabela 1 - Classes do uso do solo com sua respectiva abrangência para a área urbana do município de Nova Palma.

\begin{tabular}{r|r|r}
\hline Classe & \multicolumn{1}{|c|}{ Áreakm ${ }^{2}$} & Abrangência \% \\
\hline Floresta & 557,66 & 29,07 \\
\hline Campo & 320,83 & 16,73 \\
\hline Solo exposto & 479,99 & 25,02 \\
\hline Área Construída & 559,69 & 29,18 \\
\hline Total & 1918,17 & 100,00 \\
\hline
\end{tabular}

Fonte: Imagem Google Earth, organizado pelo autor.

O uso do solo causa influência direta no ambiente subsuperficial, pois tudo que acontece na superfície é refletido no subsolo. A partir da espacialização de uso do solo observa-se que a distribuição das classes está 


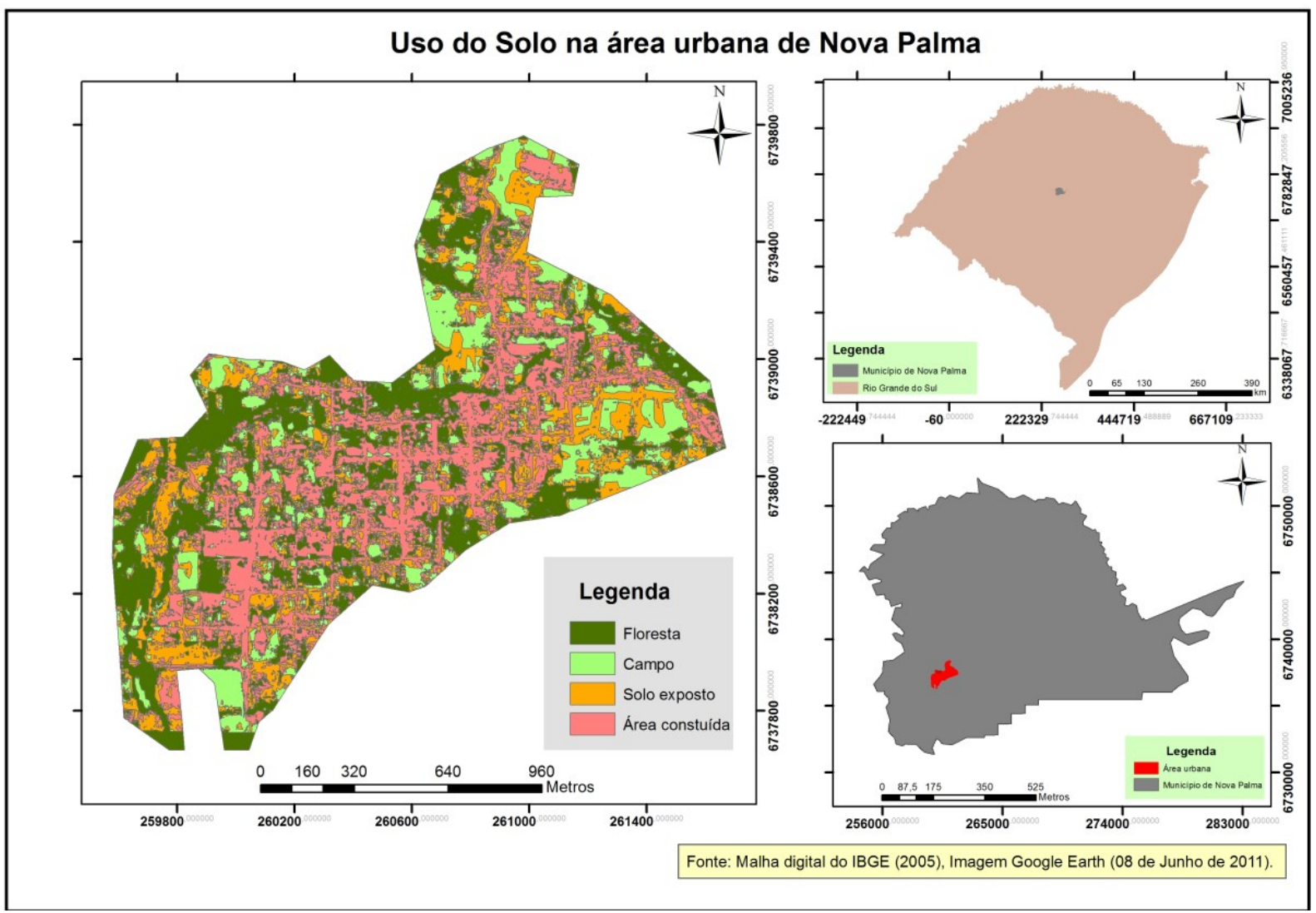

Figura 1 - Mapa de uso do solo para a área urbana de Nova Palma e seu posicionamento no estado do RS.

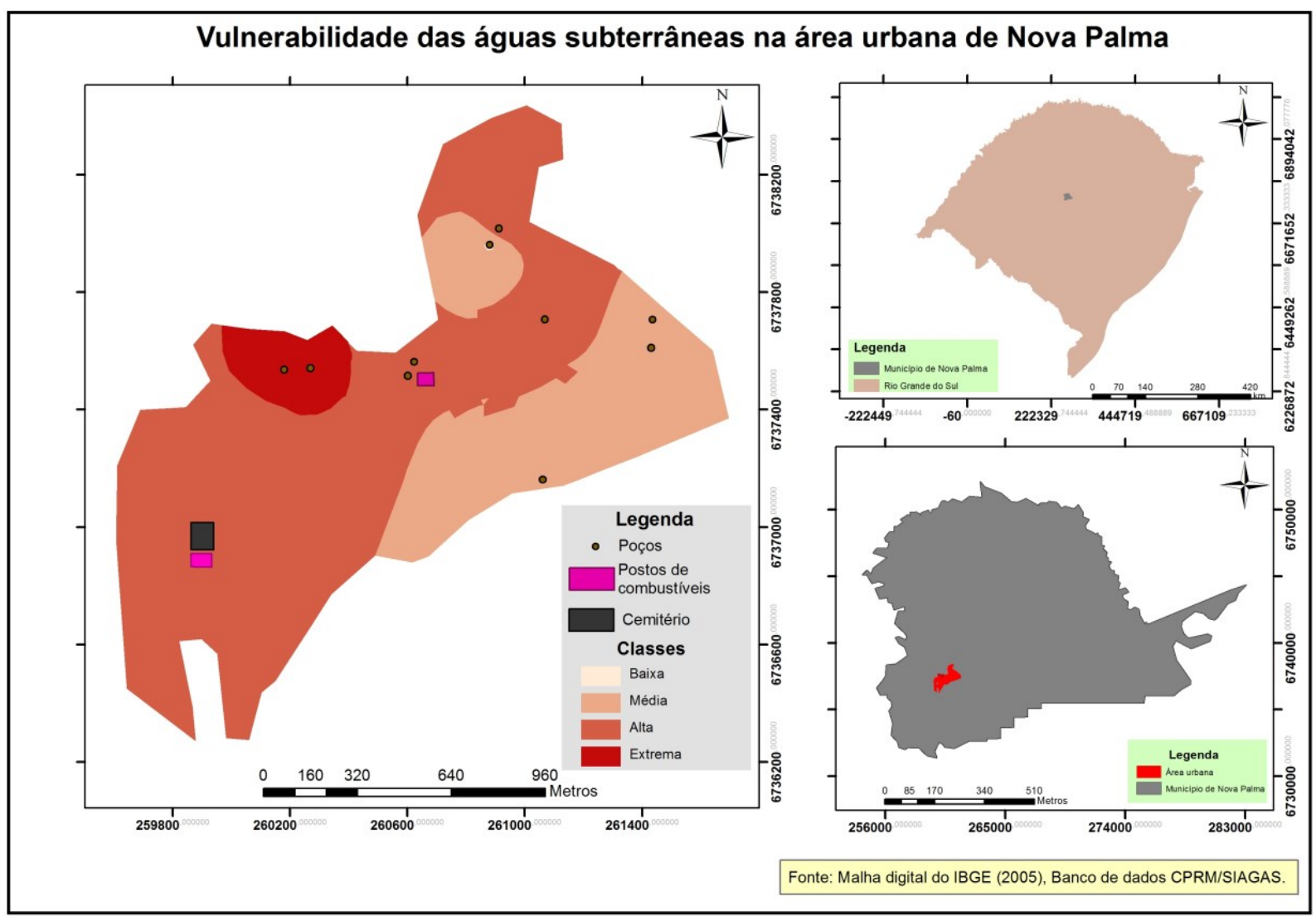

Figura 2 - Mapa da vulnerabilidade do aquífero a contaminação na área urbana do Município de Nova Palma com indicação de pontos de contaminação. 
equilibrada, ou seja, não há predominância de classe em determinados setores (Figura 1).

Com a aplicação do sistema GOD foram encontradas quatro classes de vulnerabilidade das águas subterrâneas na área urbana do município de Nova Palma: baixa, média, alta e extrema. O percentual verificado em cada uma das classes é apresentado na tabela 2.

Tabela 2 - Classes de vulnerabilidade com uso do sistema GOD com sua abrangência para a área urbana do município de Nova Palma.

\begin{tabular}{c|c|c}
\hline Classes & Área $\mathrm{km}^{2}$ & Abrangência (\%) \\
\hline Baixa & 0,63 & 0,03 \\
\hline Média & 539,45 & 28,12 \\
\hline Alta & 1276,80 & 66,56 \\
\hline Extrema & 101,45 & 5,29 \\
\hline Total & 1918,33 & 100,00 \\
\hline
\end{tabular}

Fonte: Dados SIAGAS/CPRM, organizado pelo autor.

A classe com maior cobertura foi à alta, com aproximadamente $66 \%$ da área total. A classe de vulnerabilidade média foi a segunda maior, totalizando $28,12 \%$. As classes extrema e baixa representaram, respectivamente: $5,29 \%$ e $0,03 \%$ do total da área avaliada (Figura 2).

Foi possível também, através das técnicas de geoprocessamento, estimar a localização e a área ocupada pelos pontos potencias de contaminação. Todos os pontos encontram-se em áreas de alta vulnerabilidade Esse resultado mostra a importância de políticas públicas que objetivem o planejamento de uso e ocupação do solo por empreendimentos potencialmente poluidores.

Para os postos de combustíveis não foi determinada a área do ponto por geoprocessamento, já que os reservatórios são subterrâneos, portanto não há como estimar esse valor. O cemitério municipal, indicado no mapa da figura 2, possui uma área de $7139,7 \mathrm{~m}^{2} \mathrm{e}$ situa-se na área urbana onde existem varias captações de água subterrânea do SAG, por poços tubulares.

\section{Conclusões}

A área urbana do município de Nova Palma é abastecida unicamente por águas subterrâneas do SAG. Isso faz com que a gestão desse recurso hídrico tenha muita importância no município

No estudo foram encontradas quatro classes de vulnerabilidade, desde a classe baixa a alta. A classe que apresentou maior abrangência no mapa foi a alta, portanto faz-se necessário o monitoramento contínuo do aquífero na área, bem como uma avaliação da carga contaminante a ser aplicada na instalação de empreendimentos.

Como os pontos contaminantes estão localizados em área de classe alta de vulnerabilidade, orienta-se que a administração municipal siga o que dispõe as resoluções do CONAMA, para garantir a integridade do meio ambiente aquífero. Também é necessário que futuros empreendimentos poluidores, além de seguir as legislações, também tenham seu licenciamento ambiental guiado por este estudo.

\section{Agradecimentos}

Agradecimentos à FAPERGS e à CAPES pelo auxílio através de bolsa de pós-graduação

\section{Referências}

ARAÚJO, A. O. et al. Avaliação da capacidade de infiltração de solos submetidos a manejo florestal de vegetação nativa na Chapada do Araripe. In: CONGRESSO INTERNACIONAL DE MEIO AMBIENTE SUBTERRÂNEO, 1, 2009, São Paulo. Anais eletrônicos... São Paulo: Acqua Consultoria, 2009. 1CD-ROM.

BAHIA, V. E. et al. Diagnóstico sobre contaminação das águas subterrâneas na área do Parque Estadual do Utinga, Belém-PA, pelos métodos elétrico e eletromagnético. Revista Brasileira de Geofísica, v. 29, n. 4, 2011.

CUSTODIO, E.; SILVA JUNIOR, G. C. conceptos básicos sobre o papel ambiental das águas subterrâneas e os efeitos da sua exploração. Boletin Geológico y Mineiro. 119 (1) p. 93-106. 2008.

FOSTER et al Proteção da Qualidade da Água Subterrânea: um guia para empresas de abastecimento de água, órgãos municipais e agências ambientais. São Paulo. Servemar. 2006.

FOSTER, S.; HIRATA, R.; ANDREO, B. The aquifer pollution vulnerability concept: aid or impediment in promoting groundwater protection?. Hydrogeology Journal, v. 21, n. 7, p. 1389-1392, 2013.

FIQUEPRON, J.; GARCIA, S.; STENGER, A. Land use impact on water quality: valuing forest services in terms of the water supply sector. Journal of environmental management, v. 126, p. 113-121, 2013.

FRAGA, C, M. et al. Vulnerabilidade de águas subterrâneas à poluição na bacia hidrográfica do Rio Sôrdo - Nordeste de Portugal. Revista Escola de Minas. 2013 vol:66 iss:1 pg:49 -58 
KEMERICH, P. D. da C. et al. Determinação da vulnerabilidade natural à contaminação da água subterrânea no bairro Nossa Senhora do Perpétuo Socorro em Santa Maria-RS. Engenharia Ambiental: Pesquisa e Tecnologia, v. 8, n. 3, 2011.

KURODA, K. et al. Assessment of groundwater pollution in Tokyo using PPCPs as sewage markers. Environmental science \& technology, v. 46, n. 3, p. 1455-1464, 2012.

LÖBLER, C. A. et al. Pontos Potenciais de Contaminação e Vulnerabilidade Natural das Águas Subterrâneas do Município de Restinga Seca-RS. Revista Brasileira de Geografia Física, v. 6, n. 3, p. 500-509, 2013.

RIBOLZI, O. et al. Land use and water quality along a Mekong Tributary in Northern Lao PDR. Environmental management, v. 47, n. 2, p. 291-302, 2011. 